\title{
単語知識を必要としない高精度な言語モデル
}

\author{
森大毅 ${ }^{\dagger}$ 阿曽弘具 ${ }^{\dagger}$ 牧野 正三十
}

本論文では，知識に依存しない，高い曖昧性削減能力を持つ新しい言語モデルを提案 する。このモデルは superword と呼ぶ文字列の集合の上の $n$-gram として定義され，従 来の単語や文字列の $n$-gram モデルを包含するものになっている. superword は訓練テ キスト中の文字列の再現性のみに基づいて定義される概念であり，Forward-Backward アルゴリズムによって学習される．実験の結果， superwordに基づくモデルと文字の trigram モデルを複数融合させたモデルの優位性が示され, 形態素解析に基づく方法 および高頻度文字列に基づく方法を上回る性能が得られた。

キーワード：言語モデル, superword, n-gram, 音声認識, 文字認識

\section{Precise Language Models Requiring No Lexical Knowledge}

\author{
Hiroki Mori ${ }^{\dagger}$, Hirotomo $\mathrm{AsO}^{\dagger}$ and Shozo MAKINo ${ }^{\dagger \dagger}$
}

This paper proposes a novel, knowledge-free language model with great ability in reducing ambiguity. This model is defined as $n$-gram of string which is referred to "superword," and belongs to a superclass of traditional word or string $n$-gram models' class. The concept of superword is based on only one principle-repetitionality in training text. The probabilistic distribution of the model is learned through the forward-backward algorithm. Experimental results showed that the performance of superword model combined with character trigram model was superior to the traditional word model based on morphological analysis, and traditional string-based model.

KeyWords: Language model, Superword, n-gram, Speech recognition, Character recognition

\section{1 はじめに}

音声認識・文字認識の精度向上のため, より高い性能を持つ言語モデルを求めることは重要 である．近年は，モデル構築やメンテナンスの容易さの点から，コーパスに基づく統計的言語モ デルの研究が盛んである. 大語彙ないしタスク非依存のシステムのための統計的言語モデルと して今日もっとも有望視されているものに, $n$-gramが挙げられる. $n$-gramは大量のテキスト コーパスからの単純な数え上げによって得られる統計量であり, 強力かつ頑健性に優れている.

英語などのヨーロッパ系言語においては， $n$-gramの単位として単語を用いることが多い.

†東北大学大学院工学研究科, Graduate School of Engineering, Tohoku University ††東北大学大型計算機センター, Computer Center, Tohoku University 
大語彙のシステムでは単語はカテゴリ数が非常に大きくなるため，単語の代わりに品詞を用い る (Nagata 1994)，または単語クラスタリングによって得られる単語クラスを用いることが多 い.これらの言語においては単語は分かち書きされるため機械的に取り出すことができ，数え 上げも容易に行える.

これに対し，日本語や中国語には分かち書きの習慣がない．朝鮮語は文節ごとに分かち書き をするが，その分かち方は一定しないうえ， $n$-gramの単位としては大き過ぎて汎化性に難があ る.よって，これらの言語を $n$-gramによってモデル化する際には，テキストコーパスに何らか の前処理が必要である。これには次の可能性が考えられる。

・ 人手によって分割された夕グ付きコーパスを使う

・ 自動形態素解析システムによって単語に分割する

- 経験的な統計基準によって文字列に分割する

このうちタグ付きコーパスを使う方法には，コーパス自体の入手が質的・量的な困難を伴うと いう久点がある。形態素解析に基づく方法は有効であるが，モデルを学習するためにはまず形 態素解析システムを用意せるばならないうえ，特定夕スクに対して高い性能を得るためには予 辞書をチューニングする必要があると考えられ，メンテナンスのコストがかかる。また，形 態素解析システムの文法規則によっては機能語が短めに分割される傾向があり, $n$-gramの性能 を必ずしも最大にするものではない.

これらの手法に対して，伊藤ら (伊藤, 好田 1996)は統計的な基準によって文字列の集合を選 定し，その文字列に分割されたテキストを使って $n$-gram を学習する方法を提案している. 文字 列を選定する基準としては，単純な頻度，および語彙の自動獲得のために提案されている正規 化頻度 (中渡瀬 1995) の高いものから選ぶ方式が有効であったとされる.この方法は, 形態素解 析を必要としない点で優れている。しかし，抽出すべき文字列の最適な個数を見出す方法につ いては述べられていない. また，用いられている基準と言語モデルの能力との理論的関係は浅 く，最良の分割方法である保証はない.さらに，この手法ではテキストが明示的に分割される. このため，接辞を伴った語や複合語などの長い文字列が抽出された場合，その文字列を構成す るもっと短い語は出現しなかったのと同様な扱いを受けることになる．有限のテキストから沉 化性の高い言語モデルを構築したい場合に，このような明示的な分割が最良の結果を与えると は限らない。

本論文では，高い曖昧性削減能力を持つ新しい言語モデルを提案する。このモデルは, superword と呼ぶ文字列の集合の上の $n$-gram モデルとして定義される. superword は訓練テキ スト中の文字列の再現性のみに基づいて定義される概念であり，与えられた訓練テキストに対 して一意に定まる。具体的な確率分布は, 訓練テキストから Forward-Backwardアルゴリズム によって求める。訓練テキストを明示的に分割せぬまま学習を行うため, 長い文字列中の部分 文字列を「再利用」することが可能となり，少量の訓練テキストでも効率の良いモデル化が期 
待できる，本論文ではまた，いくつかのモデルの融合による汎化性の向上についても検討する.

実時間性が要求される大語彙連続音声認識システムにおいては, 緩い言語モデルを用いて 可能性をしぼり込んだ後，詳細な言語モデルによって最終出力を導く 2 パス処理が一般的であ る。本論文で提案するような字面の適格性を与える言語モデルは，ディクテーションシステム の第 2 パス，すなわち後処理用の言語モデルとして有用であるものと考えられる．また，文字 $n$-gram を用いた認識手法(山田, 松永, 川端, 鹿野 1994)を本手法に応用することも可能である.

\section{2 superword モデルの定式化}

単語 (森, 阿曾, 牧野 1996b) や文字列の $n$-gram(伊藤・好田 1996)では与えられた系列を単 語ないし文字列に分割するやり方が一意に決まらないため, これらのモデルは直前の $n-1$ 個 の単語や文字列を状態とする，隐れマルコフモデルの一種と考えられる，単語や文字列の集合 は，語彙知識として人手で与えられるか，あるいは経験的な規則に基づいて訓練テキストから 抽出されるものである。ここで定義する superword とはこれら単語や文字列を一般化したもの であるが，それらと対照的なのは，訓練テキスト中の任意の文字列を含み得る点である．ただ し，言語モデルとして意味を持つために必要最小限のヒューリスティクスは導入せねばならな い.そこで，次の条件を満たす文字列を superword と定義する。

・訓練テキスト中に最低 2 回出現する

または

- 長さ1の文字列である

訓練テキストにおける再現性の仮定は，ある文字列が何らかの言語的なまとまりを成すか否か に対する基準となるものであり，そのような基準として考え得る制約の中でもっとも緩い条件 として与えてある，すなわち，ある文字列が訓練テキスト中で 1 回しか出現しない，または 1 回 も出現しないならば，その文字列が何らかのまとまりを成すだろうという証拠は，他に人間が 知識として与えない限り得られない。

また，再現性とは独立に，長さ1の文字列は全て superword と定義している。これにより，全 ての文は少なくとも 1 通りの superwordの系列として表現できることが保証される. superword $n$-gram 確率 $P\left(w_{i} \mid w_{i-(n-1)} \cdots w_{i-1}\right)$ は, 直前に $n-1$ 個の superword の列 $w_{i-(n-1)} \cdots w_{i-1}$ が 生起したと仮定した時の superword $w_{i}$ の条件付き生起確率である.

与えられた文 $\boldsymbol{C}=C_{1} C_{2} \cdots C_{k}$ が superwordの列 $w_{1} w_{2} \cdots w_{l}$ に分割できるとき，

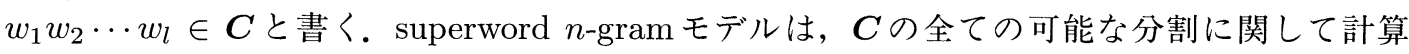
した superword $n$-gram 確率の積の総和をもって $\boldsymbol{C}$ の発生確率を推定するものである。すなわ 
ち，その確率を次式で与える。

$$
P(\boldsymbol{C})=\sum_{w_{1} \cdots w_{l} \in \boldsymbol{C}} \prod_{i=1}^{l} P\left(w_{i} \mid w_{i-(n-1)} \cdots w_{i-1}\right)
$$

ここで $n=1$ の時，すなわち superword unigram モデルは，文全体の生起確率がそれぞれ独 立な superwordの生起確率の積で表されるとするものであり, multigram(Deligne and Bimbot 1995) と呼ばれる可変長単語列に基づく言語モデルと同一のものである.

superword $n$-gram モデルのクラスは，単語や文字列の $n$-gram モデルのクラスを包含する. この性質は，パラメータさえ適切に与えることができれば, superwordに基づくモデルの性能 が単語や文字列の $n$-gram モデルの性能と同等かそれ以上になることを保証する.

\section{3 superword モデルの学習法}

\section{1 superword 集合の獲得}

モデルの獲得にあたっては，パラメータの学習に先立ち，訓練テキストから superwordの集 合を求める必要がある。長さ1の superwordについては自明であるから，再現性のある文字列 を集める作業が核心である。これには，訓練テキストの全ての位置から始まる半無限文字列を ソートして任意長 $n$-gram 統計を求め (Nagao and Mori 1994), 2 回以上出現する文字列を記録 する方法が考えられる。しかし，再現性のある文字列だけに興味がある場合には，短い文字列 から長い文字列へと逐次的に求める簡便な方法で十分である(森, 阿曾, 牧野 1996a).

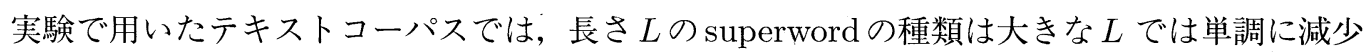
することが観察されている.

\section{2 確率分布の Forward-Backward 学習}

superword モデルでは，ある状態から別の状態に移る時に，ある確率で一つの superword を 出力する，状態は，直前 $n-1$ 個の superwordによって定まるものとする．ただし， $n=1$ の場

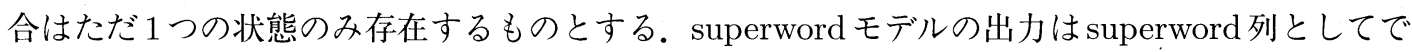
はなく文字の系列として観測される。そこで，通常の隐れマルコフモデルと同様に扱うことを 可能にするため副状態を導入して，1回の状態遷移で 1 文字を出力する等価なモデルを考える. 副状態は，状態を分割したもので，そこに移る時最後に出力した superwordの各文字に対応す る. superword $w_{i}$ の表記を $C_{1} \cdots C_{j} \cdots C_{L}$ とし， $w_{i}$ の長さ $j$ のプレフィックスを $w_{i, j}$ とする. そして, superword モデルにおける $w_{i}$ の出力を，等価なモデルでは次のように表す。すなわち， 確率 $P\left(w_{i} \mid w_{i-(n-1)} \cdots w_{i-1}\right)$ で副状態 $w_{i-(n-2)} \cdots w_{i-1} w_{i, 1}$ に移る時に $C_{1}$ を出力し, 以後確率 1 で副状態 $w_{i-(n-2)} \cdots w_{i-1} w_{i, j}$ に移る時に $C_{j}$ を出力し, 最終的に状態 $w_{i-(n-2)} \cdots w_{i-1} w_{i}$ に 至ると考える. 例として, 図1の状態遷移図では「東北大学」という superwordを出力して状態 


\section{: 状態}

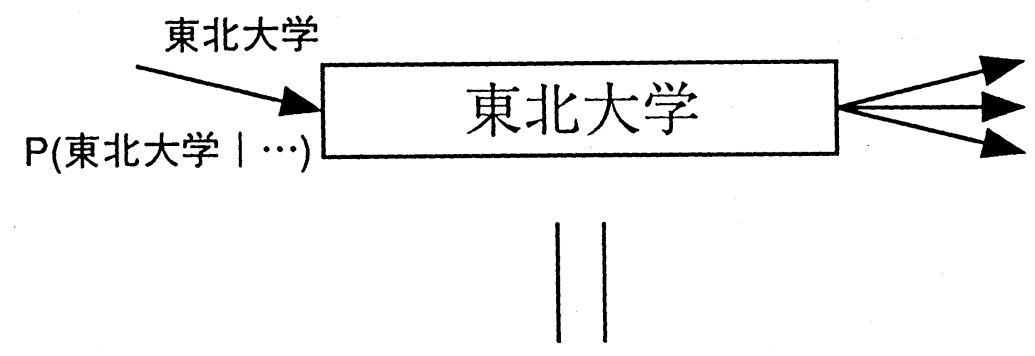

: 副状態

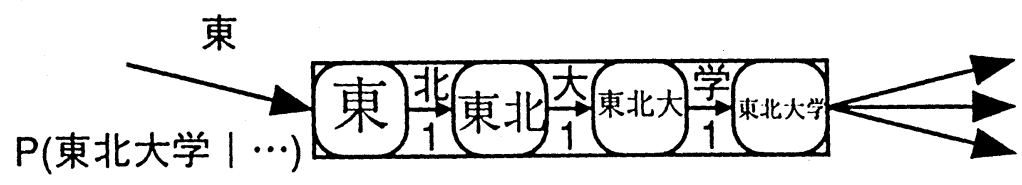

図 1 「東北大学」という superwordの各文字に対応した副状態の系列

(東北大学) に至る様子を示している，等価なモデルでは，本来の確率で副状態（東）に移る時 に文字「東」を出力，確率 $1 て ゙ （$ 東北）に移る時に「北」を出力，確率 1 で（東北大）に移る時 に「大」を出力，最終的に確率1で（東北大学）に移る時に「学」を出力する．分割前の状態 が異なる副状態は同一視しないので，例えば（東北大学）の副状態（東）と（東京）の副状態 (東)は異なることに注意すべきである。

$n=1$, すなわち superword unigram 確率の学習のための初期確率としては, 全ての superword が等確率で発生するとして, superwordの数の逆数を与える， $n>1$ については，対応す る superwordの $(n-1)$-gram 確率で初期化する.

確率の再推定のために，図2のように訓練テキストから全ての superword を洗い出す。次に, 連接可能な $n$ 個の superwordの組に関して, 次式によって確率を更新する.

$$
\frac{\tilde{P}\left(w_{i} \mid w_{i-(n-1)} \cdots w_{i-1}\right)=}{\sum_{t} \alpha_{t-1}\left(w_{i-(n-1)} \cdots w_{i-1}\right) P\left(w_{i} \mid w_{i-(n-1)} \cdots w_{i-1}\right) \beta_{t}\left(w_{i-(n-2)} \cdots w_{i}\right)}
$$

ただし， $\alpha, \beta$ はそれぞれForward確率，Backward確率で，以下のように再帰的に定義する。

$$
\alpha_{1}(w)=P(w \mid \#), \quad \text { \#は文頭を表す状態 }
$$

時刻 $t(t>1)$ で superword $w_{i}$ の第 1 字目を出力するとき

$$
\alpha_{t}\left(w_{i-(n-2)} \cdots w_{i}\right)=\sum_{w_{i-(n-1)}} \alpha_{t-1}\left(w_{i-(n-1)} \cdots w_{i-1}\right) P\left(w_{i} \mid w_{i-(n-1)} \cdots w_{i-1}\right)
$$




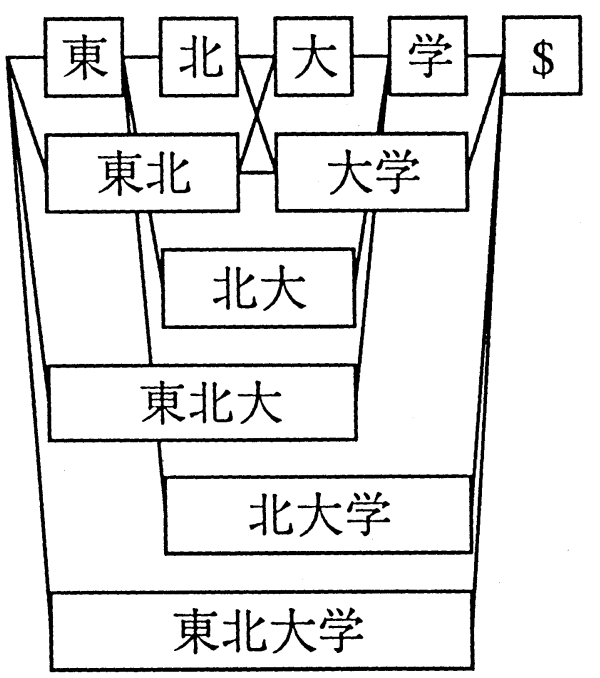

図 2 「東北大学」というテキストの解析。矩形はsuperwordを, 実線は可能なパスを表す. “\$”は文の終端

時刻 $t(t>1)$ で superword $w_{i}=C_{1} \cdots C_{j} \cdots C_{L}$ の第 $j$ 字目 $(j>1)$ を出力するとき

$$
\alpha_{t}\left(w_{i-(n-2)} \cdots w_{i-1} w_{i, j}\right)=\alpha_{t-1}\left(w_{i-(n-2)} \cdots w_{i-1} w_{i, j-1}\right)
$$

ただし

$$
\alpha_{t}\left(w_{i-(n-2)} \cdots w_{i-1} w_{i}\right)=\alpha_{t}\left(w_{i-(n-2)} \cdots w_{i-1} w_{i, L}\right)
$$

同様に

$$
\beta_{T}(\$)=1, \quad T \text { は文末記号 “\$”出力する時刻 }
$$

時刻 $t(t<T)$ で superword $w_{i}$ の第 1 字目を出力するとき

$$
\beta_{t-1}\left(w_{i-(n-1)} \cdots w_{i-1}\right)=\sum_{w_{i}} \beta_{t}\left(w_{i-(n-2)} \cdots w_{i}\right) P\left(w_{i} \mid w_{i-(n-1)} \cdots w_{i-1}\right)
$$

時刻 $t(t<T)$ で superword $w_{i}=C_{1} \cdots C_{j} \cdots C_{L}$ の第 $j$ 字目 $(j>1)$ を出力するとき

$$
\beta_{t-1}\left(w_{i-(n-2)} \cdots w_{i-1} w_{i, j-1}\right)=\beta_{t}\left(w_{i-(n-2)} \cdots w_{i-1} w_{i, j}\right)
$$

たな゙し

$$
\beta_{t}\left(w_{i-(n-2)} \cdots w_{i-1} w_{i}\right)=\beta_{t}\left(w_{i-(n-2)} \cdots w_{i-1} w_{i, L}\right)
$$

\section{4 長さ制限の導入}

再現性のある文字列の長さを十分大きく取れば，前節までに述べたモデルは与えられた訓練 テキストに対して一意に求まる。 以下では，これを一般 superword $n$-gram モデルと呼ぶ. しか 


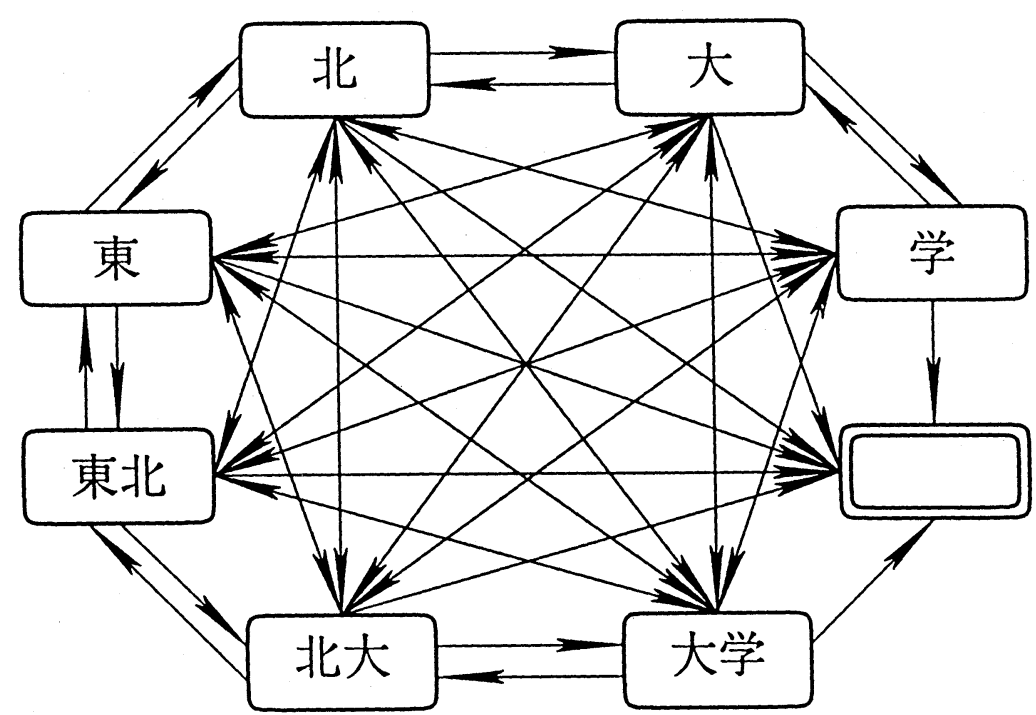

図 3 「東北大学」の部分文字列を superwordの集合とする時の長さ制限モデル

し，一般モデルのパラメータ数は大きい. 特に, $n>2$ ではsuperwordの組み合わせが爆発し， 現実的ではない。さらに，あまりに長い superwordは訓練テキストに特化してしまう恐れがあ $\eta$, 汎化能力の低下を招く.

これに対処するため，一般モデルに加えて長さ制限付きの superword モデルを導入する。こ れは，逐次的な再現性文字列の獲得を早い段階で打ち切って小さな superwordの集合をつくり， その集合に基づいて Forward-Backward 学習を行うことで得ることができる．以下では，長さl に制限された superword $n$-gram 確率を $P_{|w| \leq l}\left(w_{i} \mid w_{i-(n-1)} \cdots w_{i-1}\right)$ と表記する.

長さが $l$ に制限された superword $n$-gram モデルは，図3に示すような，状態数が高々字種の $l$ 乗に制限されたエルゴーディック HMM となる。ただし，図は $l=2$ とした例である.

\section{5 複合モデル}

$n$-gram に代表される確率モデルにおいては，モデルのパラメー夕を精度良く推定するに足 るサンプルが得られないことが多く，パラメータ空間のさまざまなスムージング法が提案され ている(Federico, Cettolo, Brugnara, and Antoniol 1995). その一つに，いくつかのモデルの確 率の重み付き線形和で表現する方法がある(Jelinek and Mercer 1980).これは本来，詳細なモ デルの值が信用できない場合に，パラメータの少ない安定したモデルの值を代用するものであ るが，性質の異なる複数のモデルを組み合わせてより良いモデルを得るという積極的な利用も 可能である．本節では，この線形補間に基づくいくつかの複合モデルを考える.

$\operatorname{superword} \operatorname{bigram}(n=2)$ モデルに対しては, superword unigram確率によって補間された 
確率は次式で与えられる。

$$
\hat{P}\left(w_{i} \mid w_{i-1}\right)=\lambda_{\mathrm{g}} P\left(w_{i} \mid w_{i-1}\right)+\left(1-\lambda_{\mathrm{g}}\right) P\left(w_{i}\right)
$$

重み係数 $\lambda_{\mathrm{g}}$ は, 訓練テキストとは別のサンプル (held-outデータ) またはクロスバリデーション によって得られる仮想的な未知データの確率を最大にするように再推定する。

前述したように，一般 superword bigramはパラメー夕量が多くなり過ぎるので，実際には superwordの長さを最大 $l$ に制限したモデルと組み合わせる。これは次式で与えられる。

$$
\hat{P}_{|w| \leq l}\left(w_{i} \mid w_{i-1}\right)=\lambda_{\mathrm{b}} P_{|w| \leq l}\left(w_{i} \mid w_{i-1}\right)+\left(1-\lambda_{\mathrm{b}}\right) P_{|w| \leq l}\left(w_{i}\right)
$$

式(12)のような制限されたモデルでは，長い語の表現に難があることも考えられる。そこ で，長さ制限付き superword bigram モデルと一般 superword unigram モデルの複合モデルを導 入する。複合 superword bigram 確率は次式で定義される。

$$
P_{\text {comp }}\left(w_{i} \mid w_{i-1}\right)=\lambda_{\mathrm{c}} \hat{P}_{|w| \leq l}\left(w_{i} \mid w_{i-1}\right)+\left(1-\lambda_{c}\right) P\left(w_{i}\right)
$$

さらに，複合 superword bigram モデルを，文字の trigram モデルによってスムージングする ことを考える，文字の trigram モデルはそれ自身で強力な曖昧性削減能力を持っているが (Mori, Aso, and Makino 1996), 単語 $n$-gram モデルと融合させることにより, 認識対象中の未知の文 字列の存在による単語解析精度の低下の影響を低減させ，頑健なモデルとすることができる(森 他 1996b)．文字によって補間された複合 superword bigram確率は次式で定義される。

$$
\hat{P}_{\text {comp }}\left(w_{i} \mid w_{i-1}\right)=\lambda_{\mathrm{w}} P_{\text {comp }}\left(w_{i} \mid w_{i-1}\right)+\left(1-\lambda_{\mathrm{w}}\right) \hat{P}_{\mathrm{c}}\left(w_{i} \mid w_{i-1}\right)
$$

ただし, $\hat{P}_{\mathrm{c}}\left(w_{i} \mid w_{i-1}\right)$ は superword $w_{i}$ が生起する確率を, 補間された文字 trigram確率の積に よって求めたものである。すなわち, $w_{i}$ の表記を $C_{1} \cdots C_{L\left(w_{i}\right)}, w_{i-1}$ の最後の 2 文字を $C_{-1} C_{0}$ と書くとき

$$
\hat{P}_{c}\left(w_{i} \mid w_{i-1}\right)=\left(\prod_{j=1}^{L\left(w_{i}\right)} \hat{P}_{\mathrm{c}}\left(C_{j} \mid C_{j-2} C_{j-1}\right)\right) \cdot d\left(L\left(w_{i}\right)\right)
$$

ただし $\hat{P}_{\mathrm{c}}\left(C_{j} \mid C_{j-2} C_{j-1}\right)$ は bigram, unigram等により補間された文字 trigram確率である。ま た, $d\left(L\left(w_{i}\right)\right)$ は文字モデルが生成する単語の長さに関する分布関数である.

\section{6 評価実験}

提案した言語モデルの能力を，文字を単位としたパープレキシティによって評価する。パー プレキシティは，式(1)において評価用テキストを $C$ として次式で求められる.

$$
P P \simeq \hat{P}(\boldsymbol{C})^{-1 / k}
$$


表 1 訓練テキスト・評価テキストの量

\begin{tabular}{|c|rr|}
\hline & 字 & (文) \\
\hline 訓練 & 969497 & $(21767)$ \\
held-out & 85654 & $(1953)$ \\
評価 & 80098 & $(1779)$ \\
\hline
\end{tabular}

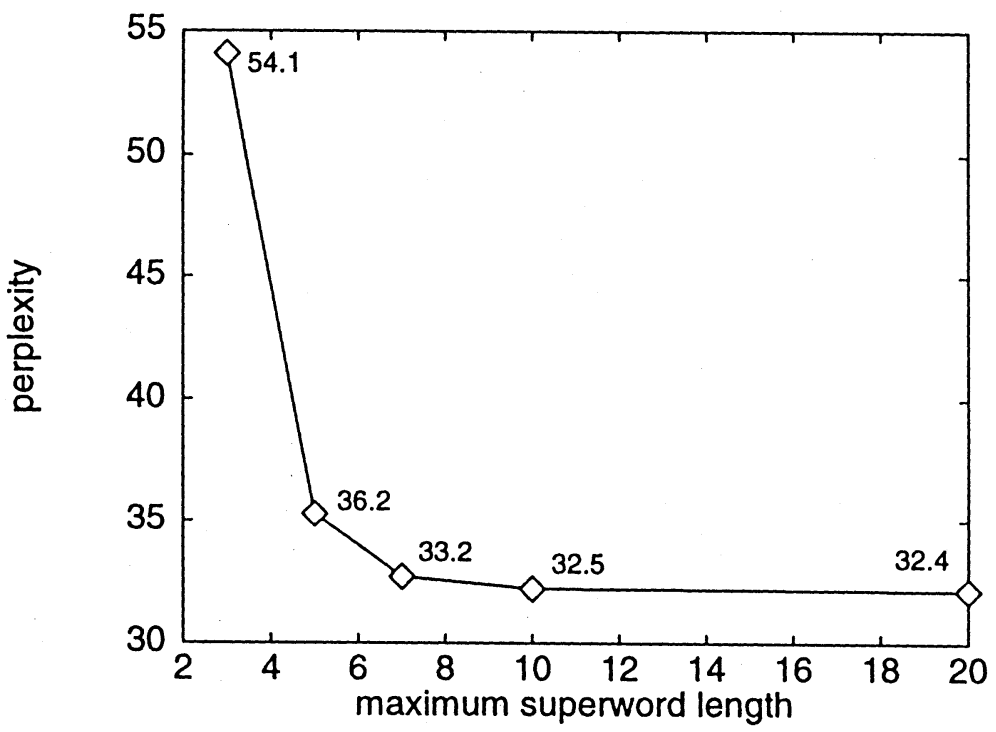

図 4 superword unigram モデルにおける長さ制限の効果

ただし， $k$ は評価用テキストの全字数である。長さ1の superwordに対しては, 確率が設定した 底值を下回る場合には底上げした，対象タスクは朝日新聞「社説」とした。実験に用いたテキ ストの量を表 $1 に$ 示す.表中, held-out とは式(12), 式(13), 式(14)の重み係数を求めるために 用いたテキストである。各々のテキストは，共通部分を持たない。

長さ制限の効果を見るため, superword unigram モデルについて最大長を変化させてパープ レキシティを求めた，その結果を図4に示す。この結果から，長い superwordを許してもパープ レキシティは上がらないことがわかる。これは, superwordの再現性の条件が適当であったこ とを示す，以下の実験では， $L=20$ の場合を一般 superword unigram モデルとして扱う。

表 2 に，提案したモデルおよび従来のモデルのパープレキシティを示す。上から 4 項目ま でが superwordに基づくモデルである。 bigramとあるのは式(12)の長さ制限付きモデルであ る.ここでは最大長を 3 とした。一般 unigram+bigram とあるのは式 (13)の複合モデル, 一般 unigram+bigram+文字とあるのはさらに文字 trigram で補間した式 (14)のモデルである。その 場合の式 (15)の分布関数としては, 指数分布を仮定した. 表 2 の残りの 4 項目は比較のために示 
表 2 各モデルの性能評価

\begin{tabular}{|c|c|}
\hline モデル & パープレキシティ \\
\hline unigram & 32.4 \\
bigram & 29.8 \\
一般 unigram+bigram & 28.5 \\
一般 unigram+bigram+文字 & 25.7 \\
\hline 文字 trigram & 28.9 \\
単語 trigram & 28.6 \\
文字+単語trigram & 26.6 \\
文字列 trigram & 28.6 \\
\hline
\end{tabular}

してある，単語 trigramは, 訓練テキストをあらかじめ形態素解析システム $\operatorname{JUMAN}($ 松本, 黒 橋, 宇津呂, 妙木, 長尾 1994)により分割して求めたものであり, 削除補間法によりスムージン グしたものである。文字十単語 trigramは，さらに文字の trigram でスムージングしたもので, 式 (15) と同様の式を用いている，文字列 trigram は，訓練テキストに伊藤らの実験(伊藤・好田 1996)で最も有効であった左最長一致による高頻度文字列への分割法を適用し, さらに文字の trigramでスムージングしたものである. 抽出文字列数は約 4000 から 12000 まで変化させ，パー プレキシティが極小となった約 6000 個を用いた時の值を示してある。スムージングのための held-outデー夕には superword モデルと同じものを用いている.

この結果から，次のことがわかる。まず，superword unigram モデルの性能が良くない，図 4 の結果をも考虑すると，これはsuperwordの長さの問題ではなく, unigramでは語と語の連接関 係が本質的に表現できないものと考えられる。これはATIS データベースの上での multigramの 評価 (Deligne and Bimbot 1995) といくぶん矛盾する結果であるが，伊藤ら (伊藤・好田 1996) も同様の結果を導いている.

長さ制限付き superword bigram モデルの導入によって, 性能の向上が見られた。しかし，ま だその性能は文字 trigramモデルに及ばない。

長さ制限付き superword bigram モデルと一般 superword unigram モデルを融合させること で，若干の性能向上が見られた。これは，長い superwordは単独ではあまり性能に貢献しない が，語と語の連接関係だけでは表現しきれない部分を補う効果を持っているものと考えること ができる。語と語の関係に関する知識と語彙知識とを独立に表現する枠組は, 形態素解析の原 理と類似している.

さらに，文字 trigram モデルでスムージングすることにより，大きく性能が向上した，その 結果，形態素解析を用いたモデルを超える性能が得られた. superwordに基づいたモデル単独 では訓練テキストに対して過学習する傾向があり，未知テキストに対して脆弱な側面があるが， 未知テキストに対して頑健な文字 trigram モデルとの融合によりそれが克服できることを意味 する。 


\section{7 あとがき}

本論文では， superwordの概念に基づいた新しい言語モデルを提案した。このモデルは従来 の $n$-gram の枠組を包含したより一般的なものであり，コーパス以外の知識に全く依存しない. また，本論文で導入した長さ制限モデルとスムージング手法により，現実的なコーパスの量の 範囲でモデルの学習が可能となった。評価実験の結果，長さ制限を施した superword bigram モ デルを文字 trigram モデルと組み合わせて頑健性を向上させたモデルの性能が高く，形態素解析 に基づく手法，および高頻度文字列抽出による方法を超える能力が得られた。

superwordに基づく言語モデルは，可搬性に優れた強力なものであるが，欠点として訓練テ キストに比べモデルの規模が非常に大きいことが挙げられる. superword unigram モデルのパ ラメータ数は superword 集合の大きさにほぼ比例する．通常の $n$-gram ではモデルのサイズの上 界がコーパスの量に対して線形のオーダーで与えられるのに対し， superwordの場合にはそれ よりも大きくなる可能性がある。これはsuperwordを可能な限り一般的に定義したためであり, 特に大規模なコーパスを用いてモデルを学習する場合には，再現性の仮定を見直す必要がある ことが考えられる。

また， superword bigram モデルは長さ制限を加えた場合でも非常に大きくなる．今回構築 した長さ 3 の superword bigram確率テーブルは約170Mbyteの大きさのファイルとなり，一般 superword unigram 確率テーブルの約 10 倍である。これは，与えられたテキストの superword による解析結果が極めて曖昧性が大きいものであることが原因である.

モデルのサイズを小さくし，実際のパターン認識システムで利用できるようにするために は，モデルの最適化が必要である。すなわち，学習の過程で非常に小さな確率を付与された状 態遷移のアークは刚り取る，あるいは外から遷移してくる確率が十分小さな状態は削除する， などである、しかし，この種の枝刚りは，訓練サンプルに特化する危険がある，今後はパープ レキシティを上げることなくモデルをコンパクトにするための枝刈り手法の開発が課題である.

\section{参考文献}

Deligne, S. and Bimbot, F. (1995). "Language modeling by variable length sequences: Theoretical formulation and evaluation of multigrams." In Proceedings of ICASSP '95, pp. 169-172.

Federico, M., Cettolo, M., Brugnara, F., and Antoniol, G. (1995). "Language modelling for efficient beam-search." Computer Speech and Language, 9, 353-379.

伊藤彰則, 好田正紀 (1996). “かな・漢字文字列の連鎖統計による言語モデル.”電子情報通信学 会論文誌(D-II), J79-D-II (12), 2062-2069.

Jelinek, F. and Mercer, R. L. (1980). "Interpolated estimation of Markov source parameters 
from sparse data." In Gelsema, E. S. and Kanal, L. N. (Eds.), Pattern Recognition in Practice, pp. 381-397. North-Holland, Amsterdam.

松本裕治, 黒橋禎夫, 宇津呂武仁, 妙木裕, 長尾真 (1994). 日本語形態素解析システム JUMAN 使 用説明書 $(2.0$ 版).

森大毅, 阿曾弘具, 牧野正三 (1996a). “再現性 $n$-gram 統計の効率的な構成法.” 1996 年電子情報 通信学会情報・システムソサイエティ大会講演論文集, D-56.

森大毅, 阿曾弘具, 牧野正三 (1996b). “文字・単語 $n$-gram の融合に基づく言語モデル.” 信学技 報 NLC96-24, 電子情報通信学会.

Mori, H., Aso, H., and Makino, S. (1996). "Robust n-Gram Model of Japanese Character and Its Application to Document Recognition." IEICE Transactions on Information and Systems, E79-D (5), 471-476.

Nagao, M. and Mori, S. (1994). "A New Method of N-gram Statistics for Large Number of N and Automatic Extraction of Words and Phrases from Large Text Data of Japanese." In Proceedings of 15th International Conference on Computational Linguistics, pp. 611-615. Nagata, M. (1994). "A Stochastic Japanese Morphological Analyzer Using a Forward-DP Backward- $A^{*}$ N-Best Search Algorithm." In Proceedings of COLING '94, pp. 201-207. 中渡瀬秀一 (1995). “統計的手法による単語の切出しについて.” 信学技報 NLC95-68, 電子情報 通信学会.

山田智一, 松永昭一, 川端豪, 鹿野清宏 (1994). “音声認識における仮名・漢字文字連鎖確率に基 づく統計的言語モデルの利用.”電子情報通信学会論文誌 (A), J77-A (2), 198-205.

\section{略歴}

森 大毅： 1993 年東北大学工学部通信工学科卒業. 1998 年同大大学院博士後期 課程修了. 博士 (工学). 同年, 同大大学院工学研究科助手. 文字認識, 音声 認識, 自然言語処理の研究に従事. 電子情報通信学会, 情報処理学会各会員.

阿曽 弘具： 1974 年東北大学大学院電気及通信工学専攻博士課程修了. 現在, 同 大大学院工学研究科教授. 並列処理, 文書認識, 音声認識, 神経回路網など の研究に従事. 平成 3 年度電子情報通信学会業績賞受賞. 工学博士.

牧野 正三: 1947 年 1 月生まれ. 1974 年東北大学大学院工学研究科博士課程修 了. 工学博士. 現在東北大学大型計算機センター及び東北大学大学院情報科 学研究科計算機ネットワーク論講座教授. 音声認識・理解, 画像処理・理解, 対話システム, 自然言語処理の研究に従事. 